IJMMS 29:2 (2002) 121-124

PII. S0161171202010141

http://ijmms.hindawi.com

(c) Hindawi Publishing Corp.

\title{
INTRODUCTION OF THE SPEAKING RATE IN THE MODEL OF SPEECH RECOGNITION
}

\author{
ABDELLAH YOUSFI and ABDELOUAFI MEZIANE
}

Received 16 February 2000

\begin{abstract}
We propose an improvement to the centisecond TLHMM model (Meziane, 1999) applied to the sound duration. Indeed, the distribution of the sound duration depends on the speaking rate. An adaptation in a post-processing step is needed. This adaptation is studied by proposing a model of the speaking rate based on average syllabic duration. The experiments elaborated on a set of BDSONS show the interest of this approach. This work is a continuation of those by Meziane (1999) and Suaudeau (1994).
\end{abstract}

2000 Mathematics Subject Classification: 68T10.

1. Introduction. General phonetic studies consider that the speaking rate of an utterance is reflected in syllable duration [2]. These studies have shown the existence of links between the duration of the phonemes and the global duration of the utterance from which they are extracted [1].

Suaudeau [3] has chosen the average syllabic duration to calculate the speaking rate, and a simple linear model to describe the influence of the speaking rate over the duration of phonemes. This model is used in a post-processing step.

DEFINITION 1.1. Let $w$ be an utterance formed by the phonemes $\phi_{k_{1}}, \ldots, \phi_{k_{\epsilon^{\prime}}}, s$ the number of syllables in this utterance, and $g(\tau)$ the observed duration of the phoneme $\phi_{k_{\tau}}$, then the average syllabic duration of this utterance is given by

$$
\text { Syl }=\frac{\sum_{\tau=1}^{\epsilon^{\prime}} g(\tau)}{S} \text {. }
$$

For each phoneme $\phi_{k_{\tau}}$, the relation between the duration $g(\tau)$ and the quantity Syl is described by the following linear speaking rate-duration model proposed by Suaudeau [3]:

$$
g(\tau)=\alpha_{k_{\tau}} \operatorname{Syl}+\beta_{k_{\tau}}+v(\tau) \quad \tau=1, \ldots, \epsilon,
$$

where $\alpha_{k_{T}}, \beta_{k_{T}}$ are the parameters of the linear model (these coefficients are estimated on the training set; this estimation gives $\bar{\alpha}_{k_{\tau}}, \bar{\beta}_{k_{\tau}}$ ).

$v(\tau)$ is a noise process with variance $\sigma_{k_{\tau}}^{2}$, where $\sigma_{k_{\tau}}^{2}$ corresponds to the duration standard variance of the phoneme $\phi_{k_{\tau}}$.

2. Use of model (1.2) in a post-processing step. To introduce model (1.2) in the centisecond TLHMM model in a post-processing phase, we have used a procedure based on the following steps. 
(1) For an utterance $w$, the recognition with the centisecond TLHMM model gives a solution $w^{\prime}$ constituted by phonemes $\phi_{k_{1}}, \ldots, \phi_{k_{\epsilon^{\prime}}}$. If $s$ is the number of syllables in $w^{\prime}$, there exists an integer $i$ such that the number of syllables composing $w$ is $s+i$, with $-N \leq i \leq N$ ( $N$ is an integer fixed in the experiments). The average syllabic duration of $w$ is, a priori, given by

$$
S^{i}=\frac{\sum_{\tau=1}^{\epsilon^{\prime}} g(\tau)}{S+i} .
$$

(2) For each value of the speaking rate $S^{i}$, we adjust the parameters of the law of duration in conformity with the model

$$
g(\tau)=\bar{\alpha}_{k_{\tau}} S^{i}+\bar{\beta}_{k_{\tau}}+v(\tau) .
$$

The new parameters of the law of duration are

$$
\bar{\mu}_{k_{\tau}}^{i}=\bar{\alpha}_{k_{\tau}} S^{i}+\bar{\beta}_{k_{\tau}}, \quad \bar{\sigma}_{k_{\tau}}^{i}=\sigma_{k_{\tau}} .
$$

(3) After adjusting the parameters of the centisecond TLHMM model, a recognition by these new parameters is undertaken. For an utterance $w$, we get $2 N+1$ solutions denoted $w_{i}^{\prime}(i=-N, \ldots, N)$, where $w_{i}^{\prime}$ is associated with the average syllabic duration $S^{i}$.

(4) For these $2 N+1$ solutions two cases exist:

(a) The $2 N+1$ solutions are identical, we do not do anything.

(b) The $2 N+1$ solutions are different. To select one of them, we use the three classic scores [3] (acoustic score, path score, duration score).

As these scores do not give satisfying results, we propose a new score called revised score, and noted score ${ }_{\text {rev }}$; it combines the three classic scores,

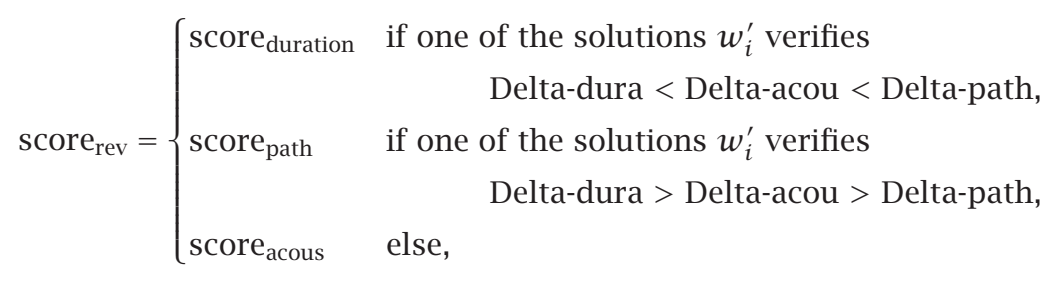

where

$$
\begin{aligned}
& \text { Delta-acous }=\frac{\operatorname{score}_{\text {acous }}\left(w_{i}^{\prime}\right)-\operatorname{score}_{\text {acous }}\left(w^{\prime}\right)}{\operatorname{score}_{\text {acous }}\left(w^{\prime}\right)}, \\
& \text { Delta-dura }=\frac{\text { score }_{\text {duration }}\left(w_{i}^{\prime}\right)-\text { score }_{\text {duration }}\left(w^{\prime}\right)}{\operatorname{score}_{\text {duration }}\left(w^{\prime}\right)}, \\
& \text { Delta-path }=\frac{\text { score }_{\text {path }}\left(w_{i}^{\prime}\right)-\text { score }_{\text {path }}\left(w^{\prime}\right)}{\operatorname{score}_{\text {path }}\left(w^{\prime}\right)},
\end{aligned}
$$

$\operatorname{score}_{\text {acous }}\left(w^{\prime}\right)$ : acoustic score of the path associated with $w^{\prime}$, score $_{\text {duration }}\left(w^{\prime}\right)$ : duration score of the path associated with $w^{\prime}$, score $_{\text {path }}\left(w^{\prime}\right)$ : path score of the path associated with $w^{\prime}$. 
TABLE 3.1. Rate of errors for the different scores.

\begin{tabular}{l|ccr}
\hline & Group 1 & Group 2 & Group 3 \\
\hline Without duration & $4.62 \%$ & $8.61 \%$ & $10.56 \%$ \\
Centisecond TLHMM & $1.54 \%$ & $3.06 \%$ & $4.17 \%$ \\
Acoustic score & $1.28 \%$ & $2.5 \%$ & $3.61 \%$ \\
Path score & $0.85 \%$ & $2.78 \%$ & $3.89 \%$ \\
Duration score & $2.14 \%$ & $2.78 \%$ & $4.17 \%$ \\
Score-rev & $2.14 \%$ & $2.22 \%$ & $3.89 \%$ \\
\hline
\end{tabular}

2.1. Likelihood of the observation sequence. Let $y_{1}, y_{2}, \ldots, y_{T}$ be the observations generated by the centisecond TLHMM model associated with the phonetic sequence

$$
\left(\wedge_{i}\right)_{1 \leq i \leq \epsilon}=\left\{\left(\phi_{k_{i}}, \theta_{i}\right) \mid i=1, \ldots, \epsilon\right\} .
$$

The likelihood of $\left(y_{1}, \ldots, y_{T}\right)$, taking into account the speaking rate $S^{p}$, is given by the formula

$$
\begin{aligned}
\operatorname{Pr} & \left(y_{1}, \ldots, y_{T}, d_{1}, \ldots, d_{\epsilon}\right) \\
= & \sum_{\xi_{T}} \pi_{i_{1}} b_{i_{1}}\left(y_{1}\right) \times\left(\prod_{n=2}^{\theta_{2}-1} a_{i_{n-1} i_{n}} b_{i_{n}}\left(y_{n}\right)\right) \times \varphi_{k_{1}}^{S^{p}}\left(d_{1}\right) \\
& \times\left(\prod_{n=\theta_{2}}^{\theta_{3}-1} a_{i_{n-1} i_{n}} b_{i_{n}}\left(y_{n}\right)\right) \times \varphi_{k_{2}}^{S^{p}}\left(d_{2}\right) \times \cdots \times\left(\prod_{n=\theta_{\epsilon}}^{T} a_{i_{n-1} i_{n}} b_{i_{n}}\left(y_{n}\right)\right) \times \varphi_{k_{\epsilon}}^{S^{p}}\left(d_{\epsilon}\right),
\end{aligned}
$$

where

(i) $\xi_{T}$ is the path of length $T$ associated with the phonetic sequence $\left(\wedge_{i}\right)_{1 \leq i \leq \epsilon}$.

(ii) $\varphi_{k}^{S^{p}}(\cdot)$ is the law of duration of the phoneme $\phi_{k}$ taking into account the speaking rate $S^{p}$. The mean and the variance of this law are $\bar{\mu}_{k}^{p}$ and $\bar{\sigma}_{k}^{p}$, respectively.

(iii) $\theta_{\tau}$ is the temporal index of the first state of the phoneme $\phi_{k_{\tau}}$.

(iv) $d_{\tau}$ is the number of the observations emitted in the phoneme $\phi_{k_{\tau}}, d_{\tau}=$ $\theta_{\tau+1}-\theta_{\tau}$.

3. Experiments. The vocabulary is composed of 20 numbers (0-19) extracted from the database "BDSONS." The experiments are achieved on three groups of speakers. The first group is composed of 13 male speakers, and the second one of 20 speakers (male, female), the third group is composed of the same speakers as the second group, but with different utterances.

The acoustic parameters are composed of the first 8 Mel frequency cepstral coefficients (MFCC).

For $N=1$, the results obtained for the different scores are as in Table 3.1.

4. Conclusion. We note that the rate of error in the third group improves when we take into account the speaking rate. We hope to get good results by developing a new score which combines more significantly the different scores. Our model is validated on a corpus formed by utterances not containing enough syllables and pronounced 
in a normal rhythm. We think that an application on a vocabulary composed of polysyllabic utterances will show significantly the interest of the introduction of this factor in the model of automatic speech recognition.

\section{REFERENCES}

[1] Y. Gong and W. C. Treurniet, Duration of phones as function of utterance length and its use in automatic speech recognition, European Conference on Speech Communication and Technology (Berlin), September 1993.

[2] M. Rossi, l'Intonation: de l'Acoustique à la Sémantique, GALF Groupe de la Communication Parlée, 1981, pp. 40-53 (French).

[3] N. Suaudeau, Un modèle probabiliste pour intégrer la dimension temporelle dans un système de reconnaissance automatique de parole [A probabilistic model to integrate temporal dimension in an automatic system of recognition of word], Thèses parole avec résumés, Université Rennes I, March 1994.

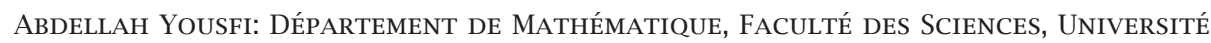
MOHAMED PREMIER, OUJDA, MOROCCO

E-mail address: yousfi . abde11 ah@sci ences . univ-oujda.ac.ma

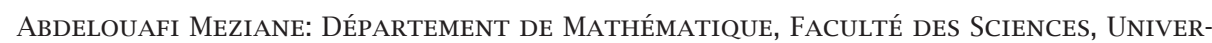
SITÉ MOHAMEd PREMIER, OUJDA, MOROCCO

E-mail address: mezi ane@sci ences .univ-oujda.ac.ma 


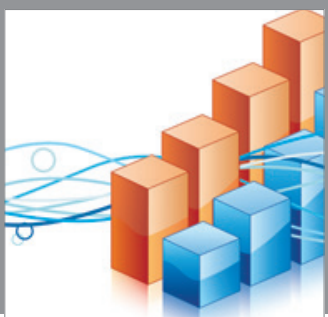

Advances in

Operations Research

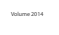

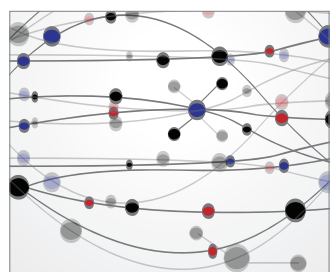

\section{The Scientific} World Journal
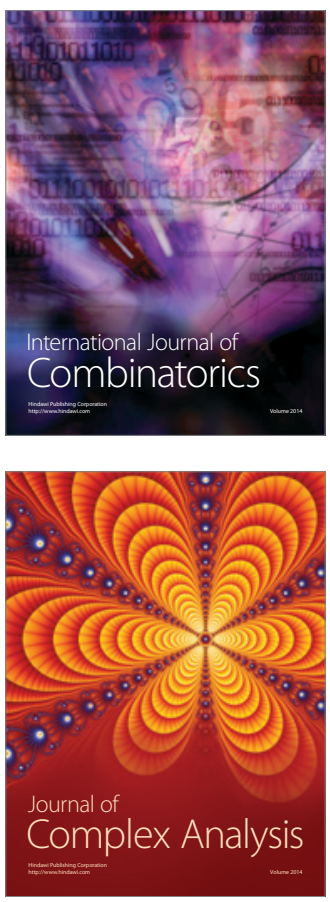

International Journal of

Mathematics and

Mathematical

Sciences
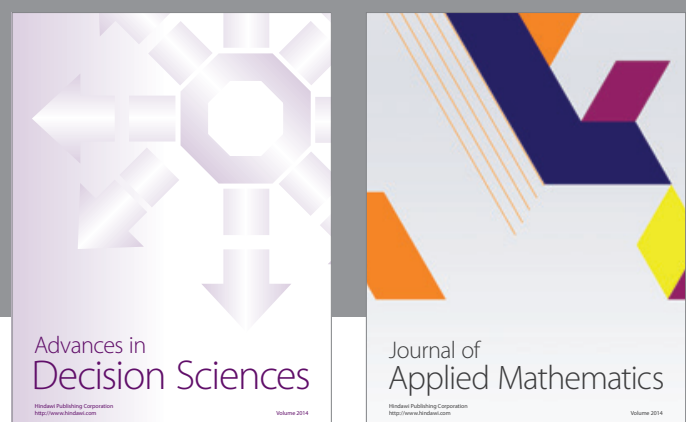

Journal of

Applied Mathematics
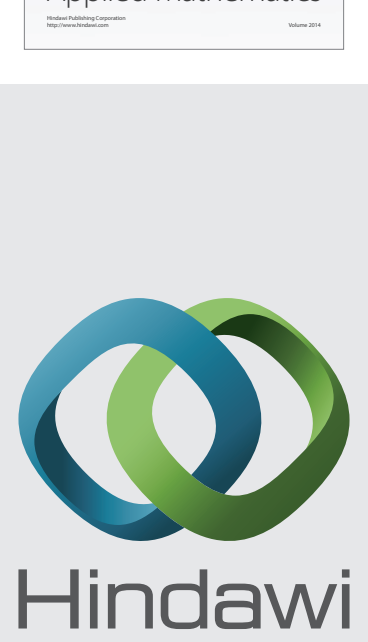

Submit your manuscripts at http://www.hindawi.com
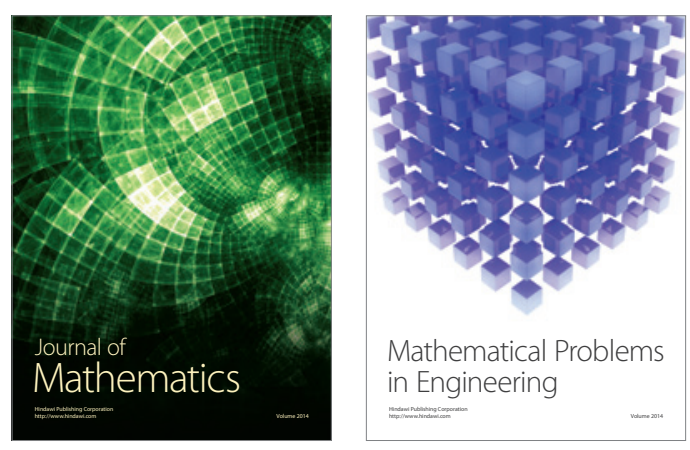

Mathematical Problems in Engineering
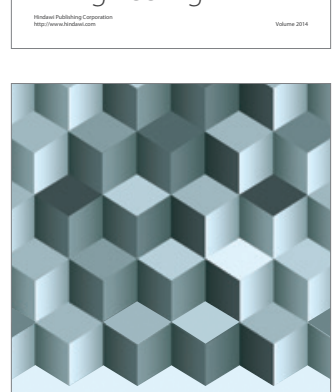

Journal of

Function Spaces
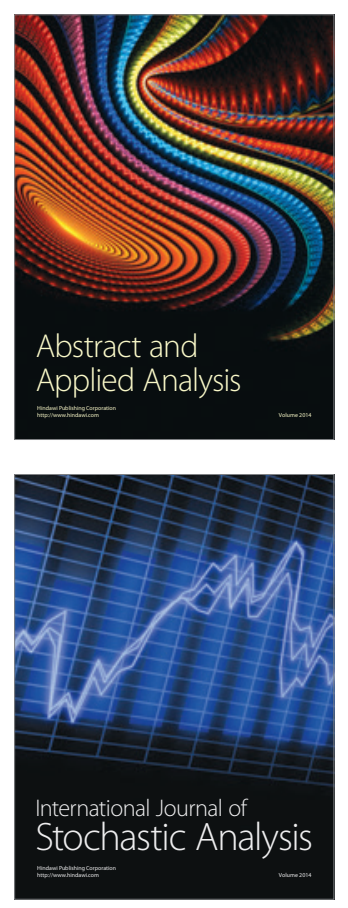

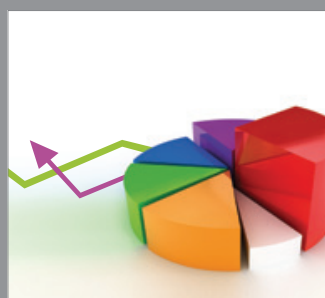

ournal of

Probability and Statistics

Promensencen
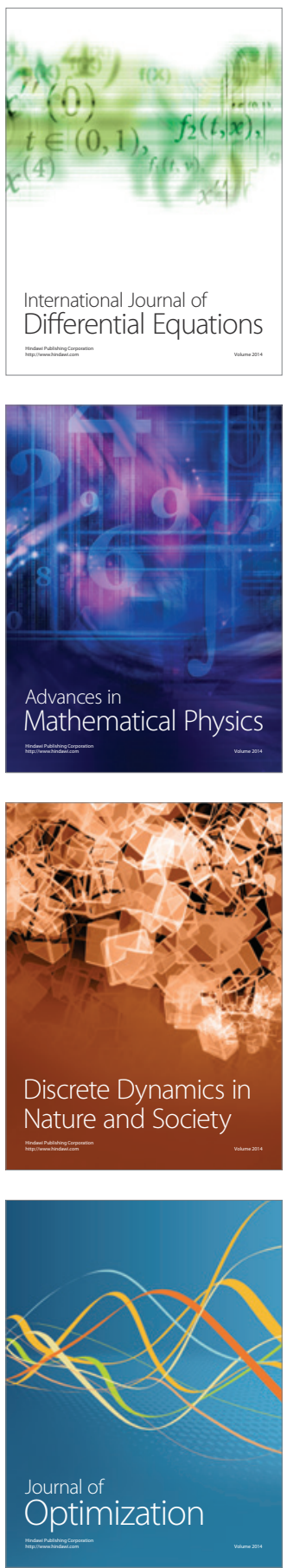